\title{
EXTRACTION OF SILICA GEL FROM RICE HUSK ASH FOR PROMISING SUSTAINABLE INDUSTRIALIZATION: STATISTICAL ANALYSIS
}

\author{
ADDIS LEMESSA JEMBERE \\ Faculty of Chemical and Food Engineering \\ Bahir Dar Institute of Technology \\ Bahir Dar University \\ Bahir Dar \\ Ethiopia \\ e-mail: addislemessa@gmail.com
}

\begin{abstract}
Recognizing the fact that rice husk is a potential biomass source of abundant silica $\left(\mathrm{SiO}_{2}\right)$, this study aimed at synthesizing silica from burnt rice husk ash. A method based on alkaline extraction followed by acid precipitation was developed to produce silica xerogels from rice husk ash. Ten grams of sample of rice husk was taken in the experiment. The process of extraction involved comprehensive techniques such as: acid washing, extraction/precipitation, filtration, centrifugation, ageing and drying. The effect of $\mathrm{NaOH}$ concentration, extraction temperature and extraction time was investigated. Apart from this, effect of washing and unwashed rice husk ash on impurity removal was analyzed quantitatively. ICP (inductively-coupled plasma emission spectrometers) was used to study the mineral present in the rice husk ash leading to investigate the degree of impurity removal. Major impurities silica produced were $\mathrm{K}, \mathrm{Ca}, \mathrm{Na}$, and Al. Statistical analysis based on ANOVA was used to determine the maximum possible yield. Regression model was used to develop an empirical model to correlate the factors. Maximum yield was noted at temperature of $60^{\circ} \mathrm{C}, 2.5 \mathrm{M}$ of $\mathrm{NaOH}$ concentration and $1.5 \mathrm{hrs}$ of extraction time. Surface area and moisture content of the gel resulted $93.4 \mathrm{~m}^{2} / \mathrm{g}$ and $3.20 \%$, respectively.
\end{abstract}

Keywords and phrases: rice husk, xerogel, silica gel.

Received September 18, 2018; Revised October 5, 2018

(C) 2018 Scientific Advances Publishers 


\section{Introduction}

World rice production is approximately 645 million tons. Asian farmers produce rice about $90 \%$ of total production of 100,000 tons or more, with two countries, China and India, growing more than half of the total crop [1].

RHA usually contains more than $60 \%$ silica $\left(\mathrm{SiO}_{2}\right), 10-40 \%$ carbon with minor mineral composition. Rice husk ash has a relatively high content of inorganic compounds, representing approximately $20 \%$ of the dry weight of the husk. Silica represents $94 \%$ of the total while the remaining $6 \%$ are $\mathrm{K}_{2} \mathrm{O}, \mathrm{CaO}, \mathrm{MgO}, \mathrm{Al}_{2} \mathrm{O}_{3}$, and $\mathrm{P}_{2} \mathrm{O}_{5}$ in decreasing concentrations [2].

Amorphous silica powder is basic raw material used in industries associated with rubber, ceramics, electronics, catalysis, pharmaceutics, dental material and other materials [3].

Silica also has been used as a major precursor for a variety of inorganic and organic metallic materials which have applications in synthetic chemistry, and in thin films or coatings for electronic and optical materials [4].

Rice husk is a widely available agricultural waste in Ethiopia. Up to recent time rise husk is largely used as animal feed, fertilizer and discarded as a waste.

Burning rice husk as fuel to generate energy results in the waste product, RHA is rich in silica and can be an economically viable raw material for production of silica gels and powders [5]. 
Studies suggested that maintaining the combustion temperature below $500^{\circ} \mathrm{C}$ under oxidizing conditions for prolonged periods or temperature up to $680^{\circ} \mathrm{C}$ with less than one minute could produce amorphous silica, Prolonged heating above this temperature may cause the material to convert, at least in part to, crystalline silica; first to cristobalite and then tridymite [6].

However, it was reported that temperature of $800^{\circ} \mathrm{C}$ maintained for 12 hours resulted in amorphous RHA silica with small proportions of crystalline silica [7]. It was also indicated that isothermal heating at a minimum of $402^{\circ} \mathrm{C}$ is required for complete destruction of organic matter from rice husk and to liberate silica [8].

The alkaline extraction method is capable of producing high purity silica but involves a significant amount of time (1-2 days) and a high number of steps with the use of various chemicals, thus resulting inexpensive production cost. In addition, the starting material for the alkaline extraction method is carbonaceous RHA containing, for example, $61 \mathrm{wt} \%$ silica and $36 \mathrm{wt} \%$ carbon, Whereby the rice husk need to be subjected first to a carbonization step to remove the organic constituents of cellulose, hemicelluloses and lignin. Rice husk is one of the more difficult fuels to burn due to its peculiar silicawood composite morphological structure, high mineral content, large bulk volume and a pronounced tendency to cake and agglomerate easily [9]. In addition, it does not combust easily or cleanly, is flame retarding and is either selfextinguishing or smoky at low temperatures [10].

Silica xerogel from RHA having 93\% silica and 2.6\% moisture and is produced by alkaline extraction followed by acid precipitation at $\mathrm{pH} 7$ and at $\mathrm{pH} 4$ with minimal mineral contaminants [11].

Apart from the alkaline extraction, there are other methods to extract silica. Some of the most common methods are: fluidized bed combustor, rotary kiln and furnace. 
Alkaline extraction is selected method for these experiment based on the following key factors:

- Relatively lower energy consumption,

- Simple method, and

- Use of low cost available chemicals.

The general objective of this experimental work is to extract and study silica gel from burnt rice husk, through this work the effect of operating conditions on the silica yield (i.e., extraction temperature, extraction time and concentration of $\mathrm{NaOH}$ ) is investigated statistically using ANOVA. Furthermore, the effect of acid washing and unwashed treatments on the impurity removal is investigated.

\section{Materials and Methods}

\section{Experimental}

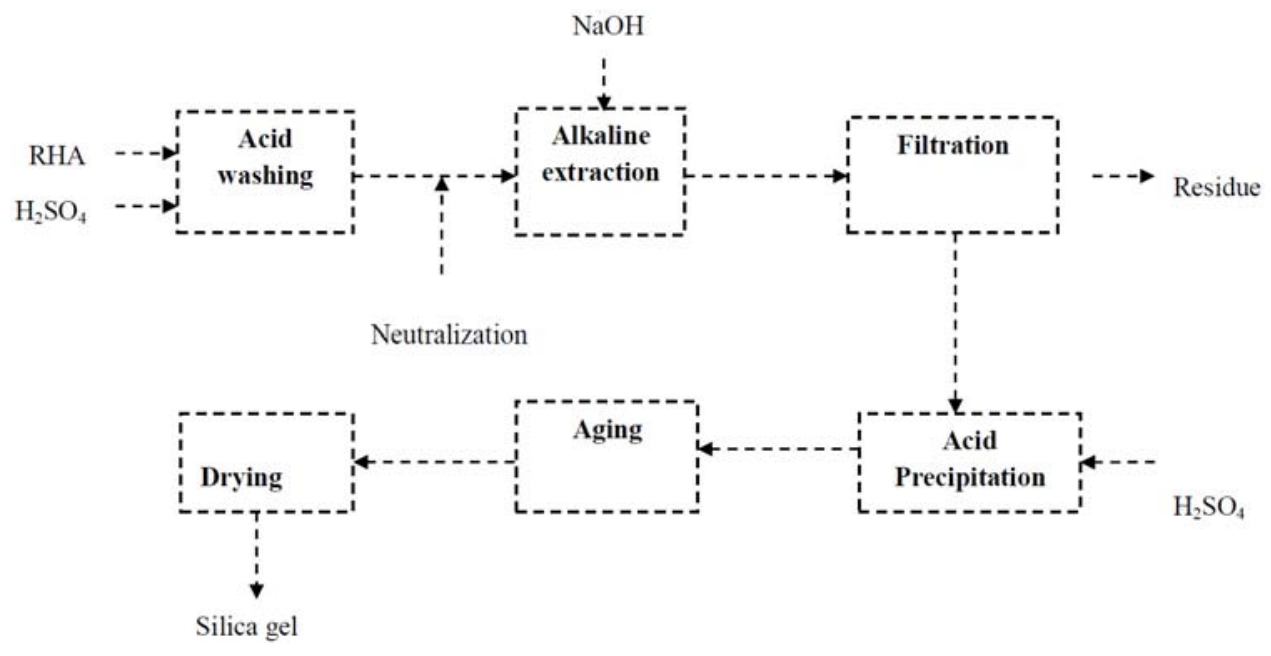

Figure 1. Experimental set up. 
The material required for these work is rice husk, Rice husk was used as the raw material for extraction of amorphous silica gel were collected from a local rice mill in Woreta, South Gonder, Ethiopia. Laboratory Experiments such as, physical analysis and extraction of silica gel were conducted in Bahir Dar Institute of Technology, Bahir Dar, Ethiopia.

Sulphuric acid (98\%) was used as precipitating agent, sodium hydroxide flake was used as a digesting agent and distilled water was used as a solvent. Figure 1 shows the sequential steps followed in the experimental.

\section{Physical properties}

\section{Ash content}

Three samples of each having $5 \mathrm{~g}$ of rice husk was weighed out, then placed in a muffle furnace at $700^{\circ} \mathrm{C}$ for 2 hours, after the specified length of time the crucible holding the samples were removed and allowed to cool slightly then placed in a desiccators until cold. The differences in weights were noted and read averaged. Percentage of ash content was calculated from the weight loss data.

$$
\mathrm{AC}=\frac{\mathrm{WD} 12}{\mathrm{~W} 1} * 100
$$

where $\mathrm{AC}$ is the ash content of the rice husk, WD12 is the weight difference between before and after burning; W1 is the initial weight of the rice husk.

\section{Moisture content}

The percentage moisture content was found by weighing $1 \mathrm{~g}$ of rice husk and placed in an oven; the samples were dried for 2 hour at $105^{\circ} \mathrm{C}$ to get rid of the moisture. The resulting sample were removed, covered and placed in desiccators. Triplicate experiment was conducted and the weight loss difference was recorded as moisture content, and the percentage of the moisture content was calculated from the data recorded 
before and after drying, percentage moisture content was calculated according to:

$$
\mathrm{MC}=\frac{\mathrm{WD}}{\mathrm{W} 1} * 100 \%,
$$

where WD is weight difference between before drying and after drying, $\mathrm{W} 1$ is initial weight of rice husk.

\section{Particle size distribution}

Particle size distribution analysis was conducted on the random sample of as received rice husk. Rice husk samples was randomly taken which their particle size ranging from the $0.5 \mathrm{~mm}-1.7 \mathrm{~mm}$, this bulk of sample were subjected to sieve analysis and their particle size distribution was recorded as shown in Table 1.

Table 1. Particle size analysis of $\mathrm{RH}$

\begin{tabular}{ccc}
\hline No. & Aperture size (mm) & Mass of particles retained (gram) \\
\hline 1 & $\leq 0.500$ & 71.60 \\
2 & $0.500-0.595$ & 53.60 \\
3 & $0.595-0.707$ & 97.48 \\
4 & $0.707-1.000$ & 0.99 \\
5 & $1.000-1.400$ & 53.07 \\
6 & $1.400-1.700$ & 38.76 \\
\hline
\end{tabular}

\section{Chemical analysis of rice husk ash}

The chemical composition of burnt rice husk ash was analyzed by using comprehensive analytical methods. Complete silicate analysis was conducted using: LIBO2 FUSION, HF attack, GRAVIMETRIC, CALORIMETRIC and AAS. 


\section{Thermal treatment}

\section{Burning of rice husk}

According to Mehta (1979) temperatures exceeding $700^{\circ} \mathrm{C}$ yield reactive amorphous ash [6]. Therefore $700^{\circ} \mathrm{C}$ was selected for burning of the rice husk, Rice husk was burned in electric furnace for 2 hours then the white ash was placed in desiccators to prevent the absorption of moisture. During combustion of rice husk, carboneous materials were burned and a clear white ash was obtained.

\section{Chemical treatment}

\section{Acid washing}

Ten grams of RHA samples were dispersed in $60 \mathrm{ml}$ of $1 \mathrm{~N} \mathrm{H}_{2} \mathrm{SO}_{4}$ distilled water, and the $\mathrm{pH}$ was adjusted to 7 with distilled water. These dispersions were stirred for $2 \mathrm{~h}$ followed by filtration using vacuumed filter through $110 \mathrm{~mm}$ ash less filter paper and then the RHA residues were washed with $100 \mathrm{ml}$ of distilled water. The filtrate was used for silica extraction while the residue were collected and dried in an evaporating dish. These dried residue containing soluble minerals were re-dissolved to determine $\mathrm{Na}, \mathrm{K}, \mathrm{Ca}, \mathrm{Mg}, \mathrm{Fe}$, and $\mathrm{Mn}$ contents using (ICP) emission spectrometer.

ICP was used for the mineral determination, the mineral were $\mathrm{K}, \mathrm{Ca}$, $\mathrm{Na}$, and $\mathrm{Al}$ for this experiment $0.25 \mathrm{~g}$ of dried RHA filitrate each from acid washing and unwashed was taken and digested using $\mathrm{H}_{2} \mathrm{O}_{2}$ and $\mathrm{HNO}_{3}$, following this $0,5,10,20 \mathrm{ppm}$ standard solution was prepared using $\mathrm{KI}, \mathrm{CaCO}_{3} \cdot 2 \mathrm{H}_{2} \mathrm{O}, \mathrm{NaCl}$, and $\mathrm{AlCl}$ at different concentration. The digestion was set in to microwave for 30 minutes at a temperature of $250^{\circ} \mathrm{C}$ to allow a complete disintegration of the samples. After the digestion process, it was allowed to cool to room temperature and diluted

with $100 \mathrm{ml}$ of distilled water and gently stired to form a miscible solution, and to settle the suspended part of the sample which has not yet 
been digested. After preparation of the solutions and samples ICP analysis taken place and the data was recorded in terms of concentration, $\mathrm{mg} / \mathrm{l}$.

\section{Alkaline digestion}

Subsequently silica was extracted using a method adapting Kamath and Proctor (1998) [9]. Sixty $\mathrm{ml}$ volumes of aqueous dispersions containing $10 \mathrm{~g}$ of the RHA and $1-2.5 \mathrm{M}$ of sodium hydroxide was heated to $30-90^{\circ} \mathrm{C}$ for various periods of time ranging from $60-120 \mathrm{~min}$. The resulting digested medium was filtered and the filtrate was readied for precipitation.

\section{Precipitation}

Two normal of $\mathrm{H}_{2} \mathrm{SO}_{4}$ was used to precipitate the dissolved silicate. Silica gels started to precipitate when the $\mathrm{pH}$ decreased to less than 10 . Figure 2 shows the schematic representation of digestion and precipitation steps.

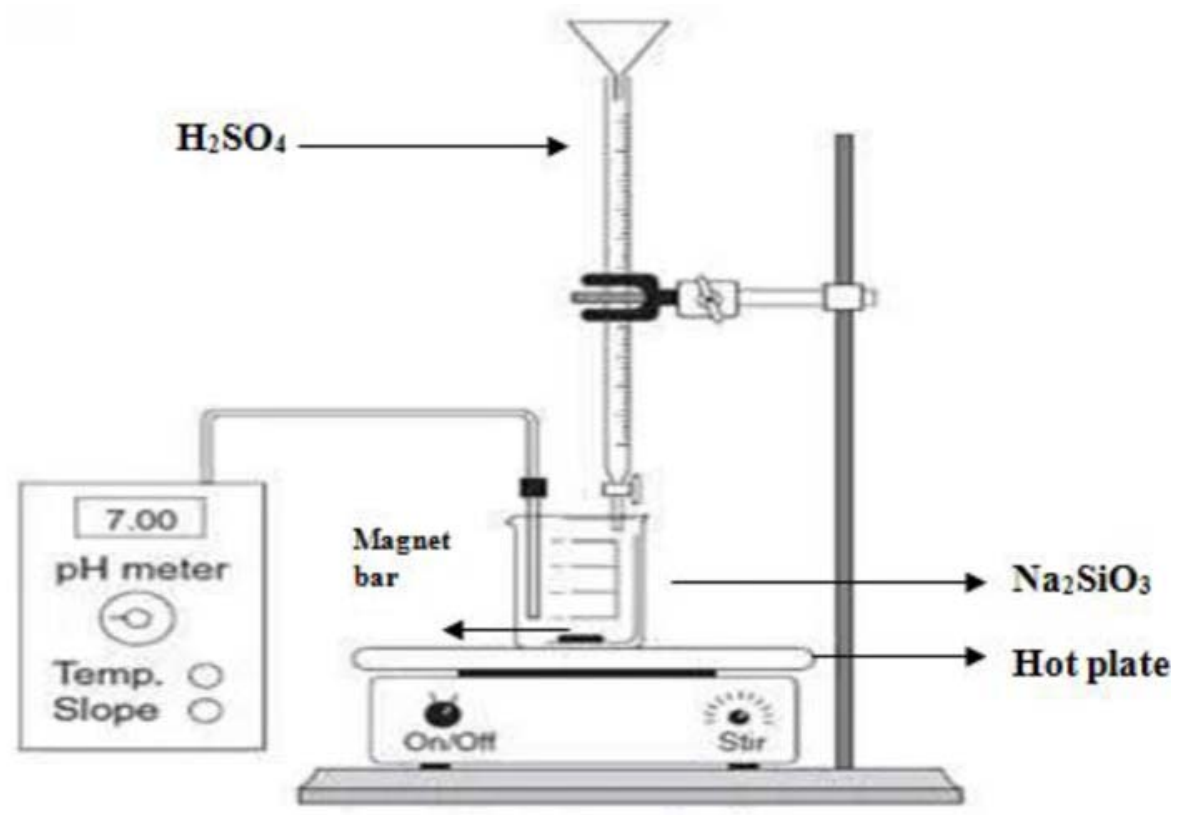

Figure 2. Alkaline digestion-precipitation. 


\section{Ageing}

The gel prepared in the first step is aged in its mother solution. This aging process strengthens the gel, so that shrinkage during the drying step is kept to a minimum. Increasing the ageing time from 1 to $12 \mathrm{~h}$ causes a considerable increase in sample surface area. Further, increasing ageing times from 12 to $96 \mathrm{~h}$ can cause reduction in surface area [12].

For particle growth and nucleation the gel was allowed to be aged for 24 hours. One hundred $\mathrm{ml}$ of distilled water was added to gels and then the gels were broken to make slurry. Slurries were then centrifuged for 15 minutes at $2500 \mathrm{rpm}$, the clear supernatants were discarded. The gels were transferred into a beaker and dried at $80^{\circ} \mathrm{C}$ for 12 hours to produce xerogels. All the samples were stored in airtight plastic bags.

\section{Experimental design}

Design Expert Software (Version 7) was used for the design of the experiment, regression, statistical analysis, and graphical analysis. A general factorial design was applied in this work to study the interaction of variables involved in the extraction of silica powder. The general factorial design is used to have factors that each has a different number of levels. It will create an experiment that includes all possible combinations of factors levels, it is widely used to study the main effect of each factors on the response and interaction.

The number of experimental runs required will be $3^{k}$ plus times replicates of the center point. Since there are only 3 levels for each factor, the appropriate model is the quadratic model.

$$
N=3^{K *} n,
$$

where $N=$ total number of experimental runs, $K=$ number of independent factors, $n=$ number of replicates. Three independent variables were considered in this study, these are (i) concentration of 
$\mathrm{NaOH}$ "A", (ii) extraction temperature "B", (iii) extraction time "C", and two replicated were considered, for each independent variables consists of three levels. This implied that 54 experimental runs and one response variables $(Y)$ were considered.

Regression Model: Each response was used to develop an empirical model that correlate the response to the three factors. Using second-order polynomial equation:

$$
Y=b_{o}+\sum_{i=1}^{n} b_{i} X_{i}+\sum_{i=1}^{n} b_{i i} X_{i}^{2}+\sum_{i=1}^{n-1} \sum_{j=i+1}^{n} b_{i j} X_{i} X_{j}
$$

where $Y$ is the predicted response, $b_{o}$ is the constant coefficient, $b_{i}$ is the linear coefficient, $b_{i j}$ is the interaction coefficient, $b_{i i}$ is the quadratic coefficient, and $X_{i}, X_{j}$ are the coded values for the factors.

Statistical and Graphical Analysis: Significance of the model equations and their terms were evaluated using statistical tools such as coefficient of determination ( $R$-squared), Fisher value ( $F$-value), probability ( $P$-value), and residual. Graphs were employed to analyze the combined effect of factors on responses using 3D plots and also to analyze the predicted versus actual value plots of the response variables. Table 2 summarizes the general factorial for the experimental design. 
Table 2. General full factorial design summery for the extraction of silica from RHA

\begin{tabular}{lllllll}
\hline Study type & Factorial & & & & \\
\hline Initial design & Full factorial & & & & & \\
Runs & 54 & & & & & \\
Factor & Name & Units & Type & Low actual & High actual & Levels \\
$\mathbf{A}$ & Concentration & Molarity & Numerical & 1 & 2.5 & 3 \\
$\mathbf{B}$ & Temperature & ${ }^{\circ} \mathrm{C}$ & Numerical & 30 & 90 & 3 \\
$\mathbf{C}$ & Time & Hour & Numerical & 1 & 2 & 3 \\
Response & Name & Units & & & & \\
$\mathbf{Y}$ & Yield & $\%$ & & & & \\
\hline
\end{tabular}

The yield was calculated and recorded for each interaction by using the Equation (7):

Silica yield $(\mathrm{wt} \%)=\frac{\text { mass of extracted silica gel }(\text { gram })}{\text { mass of RHA }(\text { gram })} * 100$.

\section{Silica gel characterization}

\section{Moisture content of the gel}

Moisture content of the silica gels was determined by using an air oven method (AOAC, 1990). One gram of silica gel sample was heated in aluminum moisture pans at $130^{\circ} \mathrm{C}$ for $1 \mathrm{~h}$. The samples were cooled in desiccators and weighed. The weight loss (\%) was recorded as the moisture content of samples.

\section{BET surface area}

The measurements of specific surface area and pore volume were performed at various partial pressures using NOVA 4000e, Surface area and pore size Analyzer Quanta chrome technology. Measurements were carried out under nitrogen adsorption at liquid nitrogen temperature, the data calculated were based on nitrogen desorption isotherm at liquid nitrogen temperatures and the software provided by NOVA. Prior to BET analysis, a sample of silica gel was heated at $300^{\circ} \mathrm{C}$ for 24 hours under 
vacuum to remove physically bonded impurities from the surface of the silica micro particles, then the sample were removed from the degassing section and inserted in the analyzer, liquid nitrogen were allowed to be adsorbed by the sample. The adsorbate property is shown in Table 3 . Finally, the result were recorded as a linear plot of $1 /[W(P / P 0)-1]$ vs $P / P 0$. The specific surface area was determined by the BET multipoint method.

$$
\frac{1}{W\left(\left(P / P_{o}\right)-1\right)}=\frac{1}{W_{m} C}+\frac{C-1}{W_{m} C}\left(\frac{P}{P_{o}}\right)
$$

where $W$ is the weight of gas adsorbed at a relative pressure, $P / P_{o}$, and $W_{m}$ is the weight of adsorbate constituting a monolayer of surface coverage. The term $C$, the BET $C$ constant, is related to the energy of dsorption in the first adsorbed layer and consequently its value is an indication of the magnitude of the adsorbent/adsorbate interactions.

Table 3. Adsorbate property for the BET analysis

\begin{tabular}{ll}
\hline Property & Value \\
\hline Sample weight & $0.04 \mathrm{~g}$ \\
Analysis gas & Nitrogen \\
Bath Temp. & $77.3 \mathrm{~K}$ \\
Adorbate & Nitrogen \\
Molec. Wt. & $28.013 \mathrm{~g}$ \\
Liquid Density & $0.808 \mathrm{~g} / \mathrm{cc}$ \\
\hline
\end{tabular}

\section{Results and Discussion}

\section{Physical properties}

The physical and chemical properties of the rice husk sample, as determined from physical and chemical analyses, were as shown in Table 4. 
Table 4. Properties of rice husk and silica gel

\begin{tabular}{|l|l|l|}
\hline \multicolumn{1}{|c|}{ Properties } & From analysis & From Literature [10] \\
\hline Moisture content (\%wt) & 13.10 & $8-9$ \\
\hline Ash content (\%wt) & 19.84 & $22-29$ \\
\hline \multicolumn{1}{|c|}{ Constituent } & From analysis & From Literature [13] \\
\hline $\mathrm{SiO}_{2}(\%)$ & 84.47 & 80 \\
\hline $\mathrm{Al}_{2} \mathrm{O}_{3}(\%)$ & 3.28 & 3.93 \\
\hline $\mathrm{Fe}_{2} \mathrm{O}_{3}(\%)$ & 0.60 & 0.41 \\
\hline $\mathrm{CaO}(\%)$ & 1.00 & 3.84 \\
\hline $\mathrm{MgO}(\%)$ & 2.62 & 0.25 \\
\hline $\mathrm{Na}{ }_{2} \mathrm{O}(\%)$ & 0.58 & 0.67 \\
\hline $\mathrm{K}_{2} \mathrm{O}(\%)$ & 5.42 & 1.45 \\
\hline $\mathrm{Loss}$ on ignition & 1.84 & 8.56 \\
\hline
\end{tabular}

From the result, it was noted that the raw rice husk contained large amount of moisture content which is higher than the study reported [10]. The ash content from the analysis was $19.84 \%$, lower than the study sited. Chemical compositions of rice husk vary from sample to sample. This variation is due to differences in climatic and geographical conditions, type of paddy etc. [14-16].

\section{Acid washing}

Table 5 shows the mineral present in the rice husk ash prior to extraction. Silica in its pure form will have high melting point but in the presence of impurities like alkaline earth metal will lower the melting point [17]. From the ICP analysis, the major impurities removed from the acid washing pretreatment were aluminum $(142.18 \mathrm{mg} / \mathrm{l})$, calcium $(80.72 \mathrm{mg} / \mathrm{l})$, potassium $(78.46 \mathrm{mg} / \mathrm{l})$, and sodium $(37.07 \mathrm{mg} / \mathrm{l})$. Aluminum which is the second highest chemical constituent of RHA removed in higher extent; on the other hand sodium was removed in small amount. The other minerals were foreign materials that might be mixed during rice handling, milling, harvesting of rice etc. this would be detected in 
ICP even if it is in small quantity. Due to the effectiveness of acid washing in terms of removal of impurities, all the experiments were conducted using acid washing pretreatment.

Table 5. ICP result for the removal efficiency of acid washing and unwashed RH

\begin{tabular}{|c|c|c|}
\hline \multirow{2}{*}{ Minerals (ppm) } & \multicolumn{2}{|c|}{ Washing types } \\
\cline { 2 - 3 } & Acid washing(mg/l) & Unwashed(mg/l) \\
\hline $\mathrm{Na}$ & 37.07 & 21.62 \\
\hline $\mathrm{K}$ & 78.46 & 20.92 \\
\hline $\mathrm{Ca}$ & 80.72 & 78.93 \\
\hline $\mathrm{Al}$ & 142.18 & 66.49 \\
\hline
\end{tabular}

\section{Yield for extracted silica from rice husk ash}

Responses obtained from the experiment was analyzed, the design matrix consisting of types of run, factors as randomized by the software and respective response was obtained from the experiment. From the results, it could be observed that the highest percentage of digested silica $(Y)$ of 94.5 was obtained at concentration, temperature and extraction time of $2.5 \mathrm{M}, 60^{\circ} \mathrm{C}$ and $1.5 \mathrm{hr}$, respectively. In comparison to recent studies by Kalapathy et al. [18] and Umesh et al. [4], the yield of silica was $85 \%$ and $93 \%$ digested silica was produced, respectively.

\section{Statistical data analysis}

\section{Development of regression model equation}

Standard deviation of 3.48 and relatively high $R^{2}$ value of 0.9455 with predicted $R^{2}(0.9187)$ in reasonable agreement with adjusted $R^{2}(0.9343)$.

The $R^{2}$ values of 0.9455 implied that $94.55 \%$ of the variation in silica extraction can be attributed to the three factors (A-concentration of $\mathrm{NaOH}$; B-extraction temperature; C-extraction time) considered. 
Therefore, the quadratic models were selected as suggested by the software model equations in their actual values are:

$$
\begin{gathered}
Y=83.21+14.4^{*} A+2.81^{*} B-0.15^{*} A^{*} B-2.36^{*} A^{*} C-1.11^{*} B^{*} C \\
-4.36^{*} A^{2}-5.68^{*} B^{2}-1.41^{*} C^{2} .
\end{gathered}
$$

Table 6. Regression statistics for silica yield (response $Y$ )

\begin{tabular}{llcllcl}
\hline \multicolumn{1}{c}{ Source } & Std. dev. & $\boldsymbol{R}^{\mathbf{2}}$ & $\begin{array}{c}\text { Adjusted } \\
\boldsymbol{R}^{\mathbf{2}}\end{array}$ & $\begin{array}{c}\text { Predicted } \\
\boldsymbol{R}^{\mathbf{2}}\end{array}$ & Press & Remark \\
\hline Linear & 5.08 & 0.8685 & 0.8606 & 0.8492 & 1478.06 & \\
2FI & 4.88 & 0.8858 & 0.8712 & 0.8533 & 1437.20 & \\
Quadratic & $\underline{\mathbf{3 . 4 8}}$ & $\underline{\mathbf{0 . 9 4 5 5}}$ & $\underline{\mathbf{0 . 9 3 4 3}}$ & $\underline{\mathbf{0 . 9 1 8 7}}$ & $\underline{\mathbf{7 9 6 . 8 3}}$ & Suggested \\
Cubic & 2.72 & 0.9721 & 0.9601 & 0.9432 & 556.47 & Aliased \\
\hline
\end{tabular}

The model equations selected as shown on Table 6 were further evaluated by using ANOVA component of the software. Table 7 shows that quadratic model for the silica yield has $F$-value of 84.77 indicating that the model is significant. For the model terms, $P$-value less than 0.05 implies that model term is significant and largest $F$-value signifies the model term having the most significant effect on the response. In this case, the significant model terms are $A, B, A C, A^{2}$, and $B^{2}$ while $C, C^{2}, A B$, and $B C$ are the insignificant model terms. The model term having the most significant effect on the response is $A$ with $F$-value of 616.03 and the effect is in the order $A>B^{2}>B>A^{2}>A C$.

The "Lack of Fit $F$-value" of 26.68 implies the Lack of Fit is significant. There is only a $0.01 \%$ chance that a "Lack of Fit $F$-value" this large could occur due to noise. 
Table 7. ANOVA table silica yield (model for response Y)

\begin{tabular}{|c|c|c|c|c|c|c|}
\hline Source & Sum of Squares & df & Mean Square & $F$ Value & $\begin{array}{l}p \text {-value } \\
\text { Prob }>\text { F }\end{array}$ & Remark \\
\hline Model & 9264.52 & 9 & 1029.39 & 84.77 & $<0.0001$ & Significant \\
\hline A-concentration & 7481.10 & 1 & 7481.10 & 616.03 & $<0.0001$ & Significant \\
\hline B-Temperature & 279.33 & 1 & 279.33 & 23.00 & $<0.0001$ & Significant \\
\hline C-Time & 32.86 & 1 & 32.86 & 2.71 & 0.1071 & \\
\hline $\mathrm{AB}$ & 0.58 & 1 & 0.58 & 0.048 & 0.8280 & \\
\hline $\mathrm{AC}$ & 138.60 & 1 & 138.60 & 11.41 & 0.0015 & Significant \\
\hline $\mathrm{BC}$ & 29.84 & 1 & 29.84 & 2.46 & 0.1242 & \\
\hline $\mathrm{A}^{2}$ & 173.93 & 1 & 173.93 & 14.32 & 0.0005 & Significant \\
\hline $\mathrm{B}^{2}$ & 387.45 & 1 & 387.45 & 31.90 & $<0.0001$ & Significant \\
\hline $\mathrm{C}^{2}$ & 23.76 & 1 & 23.76 & 1.96 & 0.1689 & \\
\hline Residual & 534.34 & 44 & 12.14 & & & \\
\hline Lack of fit & 504.31 & 17 & 29.67 & 26.68 & $<0.0001$ & Significant \\
\hline Pure error & 30.02 & 27 & 1.11 & & & \\
\hline Cor total & 9798.86 & 53 & & & & \\
\hline
\end{tabular}

The plots of actual versus predicted values of response $Y$ in Figure 3, show very minimal divergence of points from the diagonal indicating that these response model equations can be used to adequately represent the interaction of the three factors. However, some of the silica yield values predicted by the model were less accurate. This was due to the low $R^{2}$ and high standard deviation values of the model. 


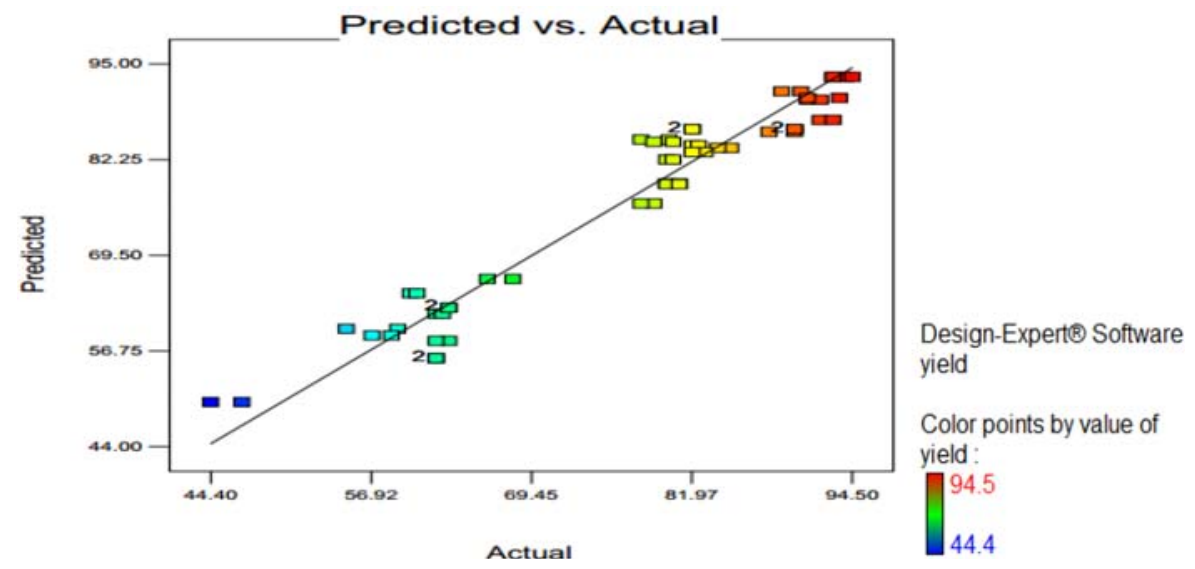

Figure 3. Actual-predicted plot for response.

\section{Combined effect of factors on response}

Combined effect of concentration and temperature at constant extraction time: Figure 4(a) shows the combined effect of temperature and concentration on silica yield. It was observed from the ANOVA that the two factors have insignificant or very small combined effect on silica yield when considering the singular effect of concentration having very significant effect. It was observed that silica yield significantly increased with increase in concentration where as increase in temperature results in relatively very small increament on silica yield.

Combined effect of concentration and extraction time at constant temperature: Figure 4(b) shows that concentration and extruction time have significant and great combined effect on silica yield. It was observed that the effect of concentration is relatively higher than that of extraction time and increase in any of the two factors increases the silica yield. It is clear to say that increasing the concentration increases silica yield but increasing the extraction time increases the silica yield slightly. But their combined effect on the silica yield was very strong. 
Combined effect of temperature and extraction time at constant concentration: Figure $4(\mathrm{C})$ shows that temperature and extraction time have insignificant or very small combined effect on silica yield. When we see the singular effects, increasing the extraction temperature increases the silica yield up to $60^{\circ} \mathrm{C}$ and it showed a slight decline trend. Increasing time didn't bring a significant effect on the silica yield.

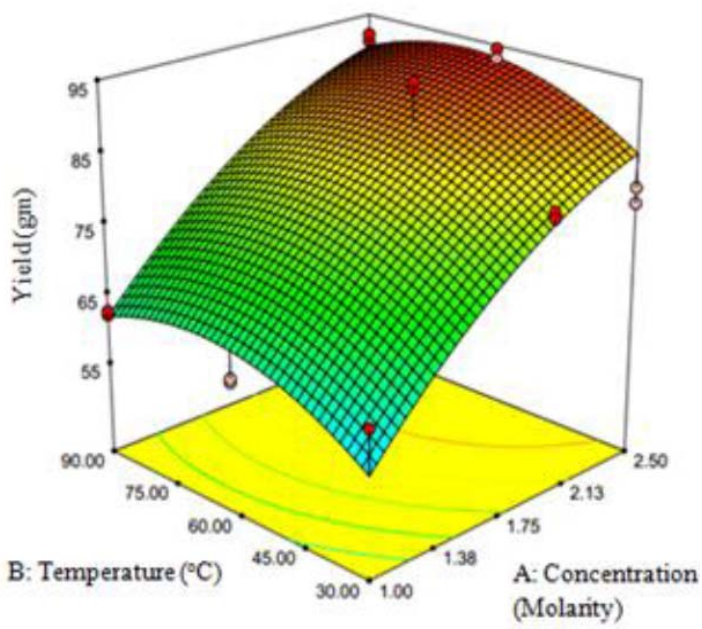

(a)

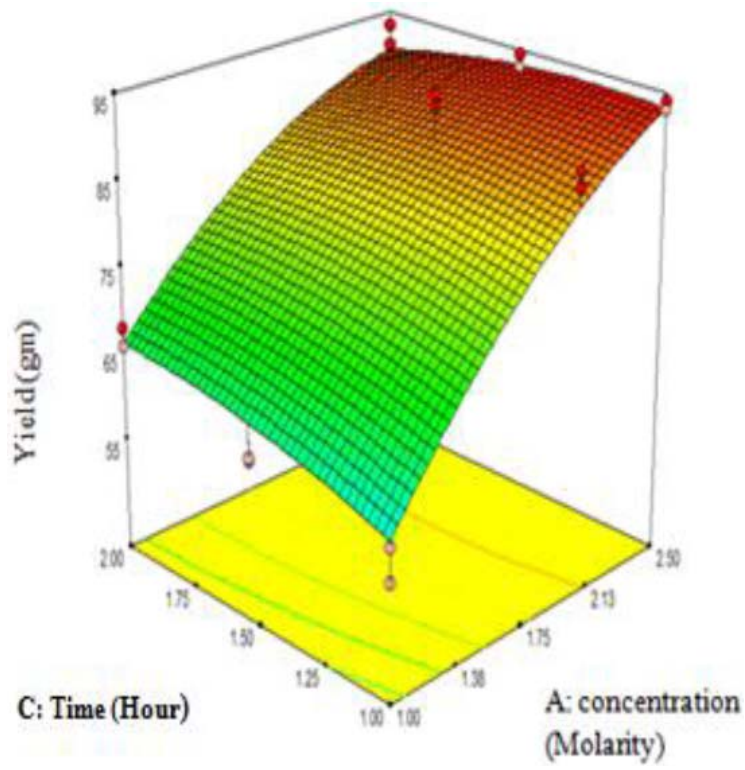

(b)
Design-Expert® Softwa

yield

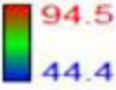

$\mathrm{Xl}=\mathrm{A}$ : concentration (Molarity) $\mathrm{X} 2=\mathrm{B}$ : Temperature $\left({ }^{\circ} \mathrm{C}\right)$

Actual Factor

C: Time $=1.50$ hour
Design-Experto Software

yield

94.5

44.4

$\mathrm{Xl}=\mathrm{A}$ : concentration (Molarity) $\mathrm{X} 2=\mathrm{C}$ : Time (hour)

Actual Factor

B: Temperature $=60.00^{\circ} \mathrm{C}$ 


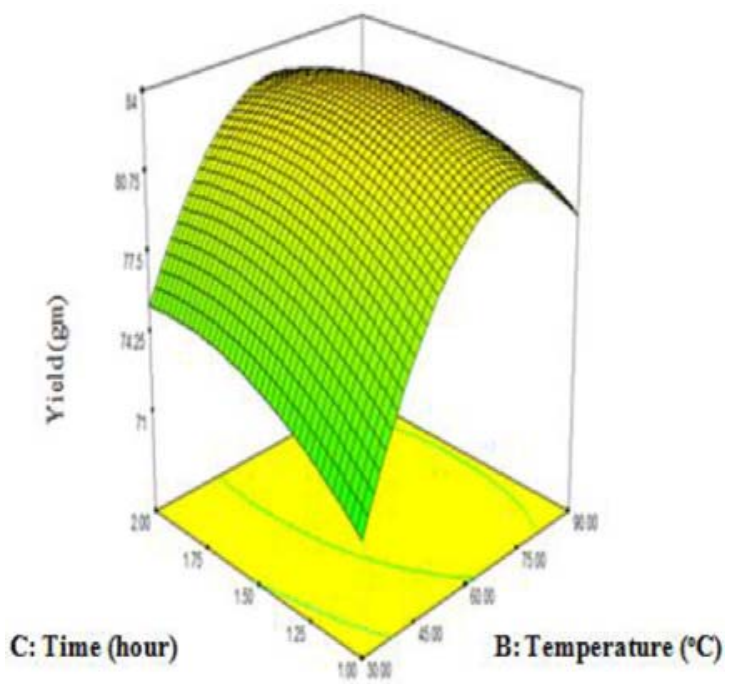

Design-Expertis Software

yield

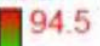

44.4

$\mathrm{Xl}=\mathrm{B}:$ Temperature $\left({ }^{\circ} \mathrm{C}\right)$

$\mathrm{X} 2=\mathrm{C}$ : Time (hour)

Actual Factor

A: Concentration $=$

1.75 Molarity

(c)

Figure 4. Combined effect of factors (a) concentration-temperature, (b) concentration-time, and (c) temperature-time on response( $Y$ ) yield.

\section{Characterization of the silica gel}

Table 8 shows the characteristics of silica gel based on specific surface area and moisture content. Specific surface area is compared to study reported. Based on the report silica xerogel is in the range. Hence among the types of silica existed (xerogel, aquagel and arogel) the extracted silca falled under the category of xerogel.

Table 8. Characteristics of extracted silica gel

\begin{tabular}{|l|c|c|}
\hline Property & Value from analysis & $\begin{array}{l}\text { Value from literature } \\
{[19,20,21]}\end{array}$ \\
\hline Moisture content (\%) & $\mathbf{3 . 2 0}$ & - \\
\hline Specific surface area $\left(\mathrm{m}^{2} / \mathrm{g}\right)$ & $\mathbf{9 3 . 6}$ & $69-152 \mathrm{~m}^{2} / \mathrm{g}$ \\
\hline
\end{tabular}




\section{Conclusion}

From the experimental work, it was able to produce $94.5 \mathrm{wt} \%$ silica yield and minimum mineral constituent. Acid washing resulted with minimal impurities in comparison with unwashed rice husk ash. The statistical analysis determine the significance of each independent variables based on this, Concentration and temperature operating parameters greatly affect the yield of silica, while extraction time doesn't have a significant effect on the yield after the optimal time, in the case of combined effect, $\mathrm{NaOH}$ concentration-extraction time was significant variable for the silica yield. Specific surface area and moisture content revealed $93.6 \mathrm{~m}^{2} / \mathrm{g}$ and $3.2 \%$, respectively. In sum method of treatment will have a determinant effect on the quality and quantity of the silica yield.

\section{References}

[1] N. Yalcin and V. Sevinc, Studies on silica obtained from rice husk, Ceramics International 27(2) (2001), 219-224.

DOI: https://doi.org/10.1016/S0272-8842(00)00068-7

[2] Dongmin An, Yupeng Guo, Yanchao Zhu and Zichen Wang, A green route to preparation of silica powders with rice husk ash and waste gas, Chemical Engineering Journal 162(2) (2010), 509-514.

DOI: https://doi.org/10.1016/j.cej.2010.05.052

[3] L. Sun and K. Gong, Review, Silicon-based materials from rice husks and their applications, Industrial and Engineering Chemistry Research 40(25) (2001), 5861-5877.

DOI: https://doi.org/10.1021/ie010284b

[4] K. V. Selvakumar, A. Umesh, P. Ezhilkumar, S. Gayatri, P. Vinith and V. Vignesh, Extraction of silica from burnt paddy husk, International Journal of ChemTech Research 6(9) (2014), 4455-4459.

[5] A. Chakraverty and S. Kaleemullah, Conversion of rice husk into amorphous silica and combustible gas, Energy Conversion and Management 32(6) (1991), 565-570.

DOI: https://doi.org/10.1016/0196-8904(91)90116-Z 
[6] P. K. Mehta, The Chemistry and Technology of Cements Made from Rice-Husk Ash, In Proceedings of UNIDO/ESCAP/RCTT, Workshop on Rice-Husk Ash Cement, Bangalore, India, 1979.

[7] R. G. Smith and G. A. Kamwanja, The Use of Rice Husk for Making a Cementitious Material, in Proc. Joint Symposium on the Use of Vegetable Plants and their Fibers as Building Material. Baghdad, 1986.

[8] J. James and M. Subba Rao, Reactivity of rice husk ash, Cement and Concrete Research 16(3) (1986), 296-302.

DOI: https://doi.org/10.1016/0008-8846(86)90104-3

[9] S. R. Kamath and A. Proctor, Silica gel from rice hull ash: Preparation and characterization, Cereal Chemistry 75(4) (1998), 484-487.

DOI: https://doi.org/10.1094/CCHEM.1998.75.4.484

[10] A. Muthadhi, R. Anitha and S. Kothandaraman, Rice husk ash properties and its uses: A Review, Journal of the Institution of Engineers 88(5) (2007), 55-56.

[11] U. Kalapathy, A. Proctor and J. Schultz, A simple method for production of pure silica from rice hull ash, Bioresource Technology 73(3) (2000), 257-262.

DOI: https://doi.org/10.1016/S0960-8524(99)00127-3

[12] T.-H. Liou and C.-C. Yang, Synthesis and surface characteristics of nanosilica produced from alkali-extracted rice husk ash, Materials Science and Engineering: B 176(7) (2011), 521-529.

DOI: https://doi.org/10.1016/j.mseb.2011.01.007

[13] Muhammad Shoaib Ismail and A. M. Waliuddin, Effect of rice husk ash on high strength concrete, Construction and Building Materials 10(7) (1996), 521-526.

DOI: https://doi.org/10.1016/0950-0618(96)00010-4

[14] V. M. H. G. Rao, Utilization of rice husk-A preliminary analysis, Journal of Scientific and Industrial Research 39(9) (1980), 495-515.

[15] N. K. Sharma, W. S. Williams and A. Zangvil, Formation and structure of silicon carbide whiskers from rice hulls, Journal of the American Ceramic Society 67(11) (1984), 715-720.

DOI: https://doi.org/10.1111/j.1151-2916.1984.tb19507.x

[16] M. Patel, A. Karera and P. Prasanna, Effect of thermal and chemical treatments on carbon and silica contents in rice husk, Journal of Materials Science 22(7) (1987), $2457-2464$.

DOI: https://doi.org/10.1007/BF01082130

[17] R. V. Krishnarao, J. Subrahmanyam and T. Jagadish Kumar, Studies on the formation of black particles in rice husk silica ash, Journal of the European Ceramic Society 21(1) (2001), 99-104.

DOI: https://doi.org/10.1016/S0955-2219(00)00170-9 
[18] U. Kalapathy, A. Proctor and J. Shultz, A simple method for production of pure silica from rice hull ash, Bioresource Technology 73(3) (2000), 257-262.

DOI: https://doi.org/10.1016/S0960-8524(99)00127-3

[19] Mari-Ann Einarsrud, Siv Haereid and Volker Wittwer, Some thermal and optical properties of a new transparent silica xerogel material with low density, Solar Energy Materials and Solar Cells 31(3) (1993), 341-347.

DOI: https://doi.org/10.1016/0927-0248(93)90128-P

[20] Samsudin Affandi, Heru Setyawan, Sugeng Winardi, Agus Purwanto and Ratna Balgis, A facile method for production of high-purity silica xerogels from bagasse ash, Advanced Powder Technology 20(5) (2009), 468-472.

[21] Jung-Kyun Hong, Hee-Sun Yang, Moon-Ho Jo, Hyung-Ho Park and Se-Young Choi, Preparation and characterization of porous silica xerogel film for low dielectric application, Thin Solid Films 308-309 (1997), 495-500.

DOI: https://doi.org/10.1016/S0040-6090(97)00486-0 